Europe's Journal of Psychology, 6(4), pp. 1-7

www.ejop.org

\title{
Etic and emic in contemporary psychological ethics
}

\author{
By Michael J. Stevens \\ Illinois State University
}

Globalization can be characterized as a process of worldwide integration through the movement of goods and capital, expansion of democratic institutions and human rights, access to information, and migration of large numbers of people. Psychology, too, has become more globalized in form and scope and in its standards for competent and ethical practice, as psychologists operate in ever more diverse and rapidly changing environments (Stevens \& Gielen, 2007). Differences in countries' ecological systems and cultural worldviews pose challenges for globalization and the globalizing of psychology, with increasing interconnectedness opposed by a movement fav oring localization. How might the seemingly contradictory forces of globalization and localization (universalism vs. particularism) manifest with regard to implementation of the Universal Declaration of Ethical Principles for Psychologists (Ad Hoc Joint Committee, 2008)?

The Universal Declaration was conceived in 2002 as common moral framework that would inspire and guide psychologists worldwide tow ard the highest ethical ideals in their professional activities. The objectives of the Universal Declaration are to provide general principles that function as a template in the development and revision of national ethics codes, as a standard that the global psychology community can use in evaluating the moral relevance of ethics codes, and as a basis for psychologists to resolve allegations of ethic al impropriety.

The International Union of Psychological Science (IUPsyS) and International Association of Applied Psychology (IAAP) established and charged an ad hoc committee with the responsibility of developing a set of universal ethical principles for psychologists. The committee included authorities on psychological ethics from Canada, China, Colombia, Finland, Germany, Iran, New Zealand, Singapore, United States, and Zimbabwe. In constructing he Universal Declaration, the committee 
plumbed historical documents from Eastern and Western civilizations in order to identify the moral foundation of ethical principles, reviewed widely accepted protections of human rights (e.g., the U.N. Declaration of Human Rights) to ascertain their underlying moral imperatives, examined ethics codes in diverse disciplines to deduce their shared principles, compared national ethics codes in psychology, and consulted, discussed, and moderated focus groups to refine the content and wording of multiple drafts.

The Universal Declaration of Ethical Principles for Psychologists was approved by the IUPsyS and IAAP in 2008 (Ad Hoc Joint Committee, 2008). The four principles that comprise the Universal Declaration are grounded in shared human values, written in generic language, and avoid the prescription of specific standards of conduct as these are to be established by each country's code of psychological ethics. The principles of the Universal Declaration include:

I. Respect for the Dignity of Persons and Peoples

II. Competent Caring for the Well-being of Persons and Peoples

III. Integrity

IV. Professional and Scientific Responsibilities to Society

There is broad consensus that the discipline of psychology is situated in culture, history, philosophy, politics, and religion, and hence must be understood from an ecological perspective (Stevens \& Gielen, 2007). Likewise, ethics codes in psychology emerge from a complex interaction of micro and macro events and forces, ultimately reflecting the values and traditions of the normative systems in which they are constituted (Stevens, 2008). And yet, psychologists have painstakingly crafted and recently adopted a set of universal guidelines for the ethical practice of scientific and applied psychology. The juxtaposition of the Universal Declaration with a perspectival framework for understanding psychology as a situated discipline raises at least two important issues regarding national ethics codes in psychology and the professional conduct of psychologists in their local milieu:

1. Is it possible for a country's psychological ethics code to mirror universal principles while at the same time embracing local norms; conversely, to what extent are universal principles and local norms irreconcilable?

2. What variables predict whether psychologists from culturally diverse countries accept, reject, or respond ambivalently to universal ethical principles as they engage in professional activities locally? 
An informal approach to establishing the cultural sensitivity and cross-cultural applicability of the Universal Declaration would be to estimate the position of each ethical principle along the continuum of Geert Hofstede's (2001) bipolar dimensions of culture. Hofstede proposed that cultures vary along five value dimensions: individualism-collectivism, power distance, uncertainty avoidance, masculinityfemininity, and time orientation (short-term vs. long-term). Such an informal analysis follows.

The values associated with Principle I on Respect for the Dignity and Worth of Persons and Peoples urge that, "all communities and cultures adhere to moral values that respect and protect their members both as individual persons and as collective peoples." This aspiration is more likely to be realized in cultures that are neither individualistic nor collectivistic, but rather mixed on this dimension. Principle II on the Competent Caring for the Well-being of Persons and Peoples is described thusly: "Competent caring... involves maximizing benefits, minimizing potential harm, and offsetting or correcting harm." These goals seem compatible with cultures that are more feminine and have a longer time orientation. The values undergirding Principle III on Integrity hold that, "Integrity is based on honesty, and on truthful, open and accurate communications... Complete openness and disclosure of information must be balanced with other ethical considerations..." These values align with cultures that tend toward lower power distance and greater femininity. The value-statements linked to Principle IV on Professional and Scientific Responsibilities to Society assert that, "As a science and profession, it [psychology] has responsibilities to society. These responsibilities include...encouraging the development of social structures and policies that benefit all persons and peoples." This statement comports with cultures inclined tow ard collectivism, high power distance, and a long-term perspective.

The above informal analysis suggest that, although it may be possible for national ethics codes in psychology to be written in such a way as to balance the ethical principles of the Universal Declaration with local norms, such a balance will be a challenge to achieve. It is worth noting that the exercise of placing each universal ethical principle along Hofstede's (2001) dimensions of culture yields fairly consistent outcomes when other typologies of culture are substituted, including Alan Fiske's (1992) forms of social reality, Harry Triandis' (1994) cultural syndromes, and Fons Trompennars' dimensions of culture (Trompenaars \& Hampden-Turner, 1998). Furthermore, the upshot of this informal analysis raises the prospect that psychologists operating in certain countries may encounter ethical-cultural dilemmas in carrying out their professional activities depending on the degree to which the ethical principles of the Universal Declaration conform to cultural norms. How are the sources of ethical compliance in vivo? 
Ronald Ingelhart and Wayne Baker (2000) have orchestrated the World Values Survey, which measures the attitudes, beliefs, and values of representative samples from 65 countries that account for $75 \%$ of the world's population. Two bipolar dimensions were extracted from the survey, namely authority and values. Authority represents a continuum ranging from traditional (i.e., absolutism) to secular/rational (i.e., relativism), whereas values runs the gamut from survival (i.e., distrust) to selfexpression (i.e., trust). These dimensions can be crossed to locate countries in a fourcelled matrix that has been used to argue that cultural heritage leaves an enduring imprint that moderates the pathways which countries take in response to modernization (both Marx and Weber were right!).

Ingelhart and Baker's (2000) typology created by crossing authority with values can also serve as a basis from which to generate predictions about the responses of psychologists, who are fulfilling professional roles at the local level, to exhortations to adopt universal ethical principles. Specifically, acceptance of universal ethics as an aspirational guideline for situated professional practice would seem more likely in countries that are characterized as secular/rational in authority and self-expressive in values (i.e., relativistic and trusting); psychologists from the nations of Oceania and Western Europe may experience little or no ethical-cultural conflict in operating within the framework of the Universal Declaration (e.g., Germany, New Zealand). Rejection of universal ethics appears more probable in countries that are more traditional in authority and survival-oriented in values (i.e., absolutist and distrustful); psychologists from African and South-Asian nations, may find overwhelming normative contradictions in the ethical ideals advocated by the Universal Declaration (e.g., Nigeria, Pakistan). Ambivalence toward the application of universal ethics in professional practice should be confined to countries located in the two remaining quadrants of the four-fold typology, that is, secular/rational in authority and survival-oriented in values (i.e., relativistic and distrustful) or traditional in authority and self-expressive in values (i.e., absolutist and trusting); psychologists from Eastern Europe and Latin America may experience uncertainty in how to reconcile the equally persuasive yet competing demands presented by the Universal Declaration and local normative systems (e.g., Russia, Argentina). Interestingly, psychologists in China and the United States would be expected to feel ambivalently, but for different reasons (China = secular/rational in authority $x$ surviv aloriented in values; USA = traditional in authority $\mathrm{x}$ self-expressive in values). For example, although respect for the individual is more strongly worded in the current iteration of China's Code of Ethics for Counseling and Clinical Practice (Chinese Psychological Society, 2007), it reminds psychologists of their ethical duties to advance social harmony and violate confidentiality when mandated by federal 
law. How might Chinese psychologists respond to the dissonance triggered by the balance between person and society promulgated by the Universal Declaration versus the Confucian virtues and communist doctrine mirrored in the Chinese code?

Application of Ingelhart and Baker's (2000) typology to the task of predicting acceptance, rejection, or ambivalence toward the Universal Declaration by psychologists practicing in different national and cultural milieus provides a platform through which to understand how the forces of globalization and localization may facilitate or temper current trends in psychological ethics. Other approaches offer attractive theoretical structures with which to examine convergent and divergent cross-national responses to the local implementation of universal ethics. These include Fathali Moghaddam's social reducton theory (Moghaddam \& Harré, 1996), which explains resistance to rapid institutional change in terms of entrenched normative systems that inform locally valid customs, and Michael Harris Bond's social axioms, which represent culture-level beliefs and expectations that act as recipes for daily living. Bond et al. (2004) have identified two social axioms, which like Ingelhart and Baker's dimensions can be transformed into a four-fold typology: dynamic externality, linked to collectivism, conservatism, hierarchy, and low national development, and societal cynicism, representing a pervasive mistrust of social systems.

While rapid globalization has weakened national boundaries and diversified populations, local normative systems persist, at times growing stronger in the face of perceived threats to cherished values and customs (Bond et al., 2004; Ingelhart \& Baker, 2000; Moghaddam \& Harré, 1996). Although the Universal Declaration of Ethical Principles for Psychologists (Ad Hoc Joint Committee, 2008) is neither a worldwide code of ethics nor a global code of conduct, its principles reflect values that to varying degrees may be impossible to incorporate into a particular country's psychological ethics code. With psychologists increasingly employed as scientists, practitioners, instructors, and consultants across cultures and countries (Stevens \& Gielen, 2007), the Universal Declaration can inspire and guide efforts to ensure that such diverse activities are responsive to the ecological conditions in which they occur. Notwithstanding the inclusiveness with which the Universal Declaration was constructed and the subsequent design of a culturally sensitive model for applying it to the development or modification of national ethics codes (see Gauthier, Pettifor, \& Ferrero, 2010), only future research, perhaps along the lines presented in this editorial, will determine its broad suitability and probability of being implemented in the practice of psychology. The Universal Declaration can be said to rest on a tenet of omniculturalism (Moghaddam, 2009), wherein individuals ideally acquire a primary identity based on shared meanings and practices as well as secondary identities 
composed of narrower in-group worldviews, with clashes between identities resolved by prevailing universal values. History is replete with the short-sightedness of such thinking.

\section{References:}

Ad Hoc Joint Committee. (2008). Universal declaration of ethical principles for psychologists. Retrieved from http://www.am.org/iupsys/ethics/univ decl2008.html

Bond, M. H., Leung, K., Au, A., Tong, K.-K., de Carrasquel, S., Murakami, F., ...Lewis, J. R. (2004). Culture-level dimensions of social axioms and their correlates across 41 countries. Journal of Cross-Cultural Psychology, 35, 548-570. doi:10.1177/0022022104268388

Chinese Psychological Society. (2007). Code of ethics for counseling and clinical practice. Retrieved from http://www.am.org/iupsys/ethics/ethic-com-natl-list.html

Hofstede, G. (2001). Culture's consequences: Comparing values, behaviors, institutions, and organizations across nations (2 ${ }^{\text {nd }}$ ed.). Thousand Oaks, CA: Sage.

Fiske, A. P. (1992). The four elements of sociality: Framew ork for a unified theory of social relations. Psychological Review, 99, 689-723. doi:10.1037/0033-295X.99.4.689

Gauthier, J., Pettifor, J., \& Ferrero, A. (2010). The universal declaration of ethical principles for psychologists: A culture-sensitive model for creating and reviewing a code of ethics. Ethics and Behavior, 20(3\&4), 1-18.

Ingelhart, R., \& Baker, W. E. (2000). Modernization, cultural change and the persistance of traditional values. American Sociological Review, 65, 19-51. doi:10.2307/2657288

Moghaddam, F. M. (2009). Commentary. Omniculturalism: Policy solutions to fundamentalism in the era of fractured globalization. Culture and Psychology, 15, 337347. doi:10.1177/1354067X09337867

Moghaddam, F. M., \& Harré, R. (1996). Psychological limits to political revolutions: An application of social reducton theory. In E. Hasselberg, L. Martienssen, \& F. Radtke (Eds.), Der dialogbegriff am ende des 20 jahrhunderts [The concept of dialogue at the end of the $20^{\text {th }}$ century] (pp. 230-240). Berlin: Hegel Institute.

Stevens, M. J. (2008). Professional ethics in multicultural and international context. In U. P. Gielen, J. G. Draguns, \& J. M. Fish (Eds.), Principles of multicultural counseling and therapy (pp. 135-166). Mahwah, NJ: Erlbaum. 
Stevens, M. J., \& Gielen, U. P. (Eds.). (2007). Toward a global psychology: Theory, research, interventions, and pedagogy. Mahwah, NJ: Erlbaum.

Triandis, H. C. (1994). Culture and social behavior. New York: McGraw-Hill.

Trompenaars, F., \& Hampden-Turner, C. (1998). Riding the waves of culture: Understanding diversity in global business (2nd ed.). New York: McGraw-Hill.

About the author:

Michael J. Stevens is a professor of psychology at Illinois State University, where he directed the master's program in counseling psychology and was named Outstanding University Researcher. He also is an honorary professor at The Lucian Blaga University of Sibiu in Romania, where he received a Doctor Honoris Causa. In 1995 Dr. Stevens was awarded a Fulbright grant to teach the first graduating class of Romanian psychologists since psychology education had been banned by the Ceausescu regime. Dr. Stevens has served as President of the APA's Division of International Psychology and Director-at-Large of the International Council of Psychologists. He is a Fellow of the APA. His interest in international psychology has led to the Handbook of International Psychology (2004), Toward a Global Psychology: Theory, Research, Intervention, and Pedagogy (2007), Teaching Psychology Around the World: Vol. 2. (2009), Psychology: IUPsys Global Resource (2005-2009), and The Oxford International Handbook of Psychological Ethics (in press). He writes and presents on as well as teaches psychological ethics.

Address for correspondence: Michael J. Stevens, Department of Psychology, Illinois State University, Campus Box 4620, Normal, IL 61790-4620, USA

E-mail: misteven@ilstu.edu 